J. Amer. Soc. Hort. ScI. 120(3):468-474. 1995.

\title{
Identifying Critical Volatiles in the Flavor of Baked 'Jewel' Sweetpotatoes [Ipomoea batatas (L.) Lam.]
}

\author{
Jyh-Bin Sun ${ }^{1}$ \\ Department of Horticulture, University of Georgia, Athens, GA 30602-7273
}

Ray F. Severson and William S. Schlotzhauer

Phytochemical Research Unit, Russell Research Center, U.S. Department of Agriculture, Athens, GA 30613

Stanley J. Kays ${ }^{2}$

Department of Horticulture, University of Georgia, Athens, GA 30602-7273

Additional index words. plant breeding, selection, postharvest, quality

\begin{abstract}
Thermal degradation of fractions from sweetpotato roots ('Jewel') was conducted with gas chromatographymass spectrometry to identify precursors of critical flavor volatiles. Upon heating $(200 \mathrm{C})$, sweetpotato root material that was insoluble in methanol and methylene chloride produced similar volatile profiles to those from sweetpotatoes baked conventionally. Volatiles derived via thermal degradation of the nonpolar methylene chloride fraction and the polar methanol fraction did not display chromatographic profiles similar to those from conventionally baked sweetpotatoes. Initial reactions in the formation of critical volatiles appear to occur in the methanol and methylene chloride insoluble components. Maltol (3-hydroxy-2-methyl-4-pyrone) was found to be one of the critical components making up the characteristic aroma of baked sweetpotatoes. Integration of an analytical technique for the measurement of flavor into sweetpotato breeding programs could potentially facilitate the selection of improved and/or unique flavor types.
\end{abstract}

Flavor, composed of taste and odor, is a primary trait utilized in the acceptance or rejection of foods and, as a consequence, is of critical importance in the selection process in plant breeding programs. While there are generally thought to be only four primary taste sensations, humans can perceive up to 10,000 distinct odors (Nursten, 1970). Aroma constituents, therefore, represent critical components in food selection. The development of an analytical technique for the quantification of volatile compounds emanating from cooked sweetpotatoes that is compatible with breeding programs (Sun et al., 1993) has increased the impetus for identifying the critical volatile flavor compounds.

A broad cross-section of volatile compounds $(\approx 50)$ emanating from baked 'Jewel' sweetpotatoes have been identified (Horvat et al., 1991; Kays and Horvat, 1984; Purcell et al., 1980; Sun et al., 1993; Tiu et al., 1985); however, none has been shown to represent critical components of the characteristic aroma. The normal sweetpotato aroma is not formed at low cooking temperatures (i.e., 85C) (Sun et al., 1994), thus, thermal reactions appear to represent an essential step in the synthesis of the characteristic aroma.

Thermal reactions are a common means of synthesizing volatile compounds during cooking. Among a broad range of possible reactions, the Maillard reaction, caramelization, and Strecker degradation are the most common mechanisms in the thermally induced synthesis of volatiles (Parliment, 1989). For example, alkyloxazoles found in french-fried potatoes are thought to be formed via Strecker degradation reactions (Carlin et al., 1986). Volatile furans and pyrans, which are formed via the Maillard reaction and/or caramelization, are frequently found in highcarbohydrate cooked foods (Fors, 1983). Since a number of the volatiles identified from baked sweetpotatoes [e.g., furfural, maltol,

Received for publication 20 June 1994, Accepted for publication 28 Oct. 1994. The cost of publishing this paper was defrayed in part by the payment of page charges, Under postal regulations, this paper therefore must be hereby marked advertisernent solely to indicate this fact.

'Current address: Food Industry Research and Development Institute, P.O. Box 246, Hsinchu, 30099, Taiwan, ROC,

${ }^{2}$ To whom reprint requests should be addressed, isomaltol (Sun et al., 1993)] are identical to those produced via the thermal degradation of carbohydrates in the presence of amino acids (Baltes et al., 1989), it is possible that the Maillard reaction plays an important role in the synthesis of the characteristic aroma of baked sweetpotatoes.

To begin to identify the precursors of critical baked sweetpotato flavor volatiles, we assessed the role of major groups of constituents, based on volubility, from the raw roots in the formation of volatiles during baking. Volatile thermolytic products from individual fractions were analyzed and compared to those from nonextracted root material. In addition, baked sweetpotatoes volatiles were fractionated using preparative gas chromatography (GC) and tested using sensory evaluation to determine critical volatiles.

\section{Materials and Methods}

Sample preparation. 'Jewel' Sweetpotatoes grown at the Univ. of Georgia Horticulture Farm were harvested, cured [29C, 95\% relative humidity $(\mathrm{RH})]$ for 7 days, and stored at $15 \mathrm{C}, 82 \% \mathrm{RH}$. The control sweetpotato volatile samples were prepared by placing 300 $\mathrm{g}$ of root material inside a glass sample container and baking at 204C for $70 \mathrm{~min}$. The volatiles produced were collected with a purge and trap system using methylene chloride as the solvent. The collection apparatus and the procedures were as previously described (Sun et al., 1993). Volatiles collected from baked sweetpotatoes were used for GC analysis and sensory evaluation. Fractionation of storage roots into groups of components based on volubility involved blending $242 \mathrm{~g}$ of root tissue in $100 \mathrm{ml}$ methanol for $1 \mathrm{~min}$. in a blender (Waring blender model 5011; Waring Products Division, New Hartford, Corm.). The homogenate was filtered under vacuum and the residue was resuspended and filtered similarly two additional times. The residue was then extracted with methylene chloride using the same procedure. The residue remaining after extraction comprised the insoluble fraction. The polar (methanol extract) and nonpolar (methylene chloride extract) fractions were taken to dryness with a rotavapor at 40C under oil pump vacuum. Individual fractions weighed 41.66 
$\mathrm{g}(17.21 \%$ fresh weight), $0.42 \mathrm{~g}(0.17 \%)$, and $15.54 \mathrm{~g}(6.42 \%)$ for the insoluble, nonpolar, and polar fractions, respectively; the remaining $72.6 \%$ fresh weight was assumed to be water.

A sugar standard of glucose, fructose, sucrose, and maltose (12 g, $12 \mathrm{~g}, 43 \mathrm{~g}$, and $36 \mathrm{~g}$, respectively, in $10 \mathrm{ml}$ distilled water) in the same ratio as in baked roots (Sun et al., 1994) was prepared to determine thermal degradation products from sugars. Methylene chloride and methanol were obtained from J.T. Baker, Phillipsburg, N.J. Glucose, fructose, sucrose, and maltose were purchased from Sigma Chemical Co., St. Louis.

Thermal degradation. Individual root fractions (insoluble, polar, and nonpolar) were heated using a pyrolysis system composed of carrier gas, a vycor glass tube, a heating chamber, and a solvent trap (Schlotzhauer and Chortyk, 1981$)$. We selected 200C $(\approx 400 \mathrm{~F})$ for all the thermal degradation experiments since the temperature is commonly used for baking sweetpotatoes. Samples were placed in a vycor glasspyrolysis tube within the heating chamber and heated from ambient $(\approx 20 \mathrm{C})$ to $200 \mathrm{C}$ for a total heating time of $30 \mathrm{~min}$. Since 200C is substantially lower than normal pyrolysis temperatures (e.g.,
$>600 \mathrm{C}$ ), the term thermolysis rather than pyrolysis is used subsequently in the text. Volatiles produced were purged from the tube using a stream of GC-grade dry air and collected in a methylene chloride trap. The methylene chloride solvent was reduced to $3 \mathrm{ml}$ with a Kudema-Danish concentrator in a steam bath and analyzed using GC with a flame ionization detector. Thermolyzed samples included the insoluble ( $2 \mathrm{~g})$, polar (2 g), and nonpolar (420 $\mathrm{mg}$ ) fractions and the sugar standard $(2 \mathrm{~g})$, maltose $(2 \mathrm{~g})$, and raw sweetpotato root tissue $(10 \mathrm{~g})$.

GC and GC-MS analysis. The compositions of individual volatile samples were subsequently analyzed using GC and characterized using GC-MS. A GC (model 5890; Hewlett-Packard, San Fernando, Calif.) with a thick-coated OV-351 fused silica capillary column $(0.3 \mathrm{~mm}$ i.d. $\times 30 \mathrm{~m})$ and flame ionization detector was utilized. The oven temperature was held at $40 \mathrm{C}$ for 2 min. and then increased to $210 \mathrm{C}$ at $3 \mathrm{C} / \mathrm{min}$. The injection port temperature was at $200 \mathrm{C}$ and the detector port $260 \mathrm{C}$. Samples were injected in the splitless mode with a purge activation time of $1 \mathrm{~min}$. A HP 5970 mass selective detector with a HP 5890 GC was used

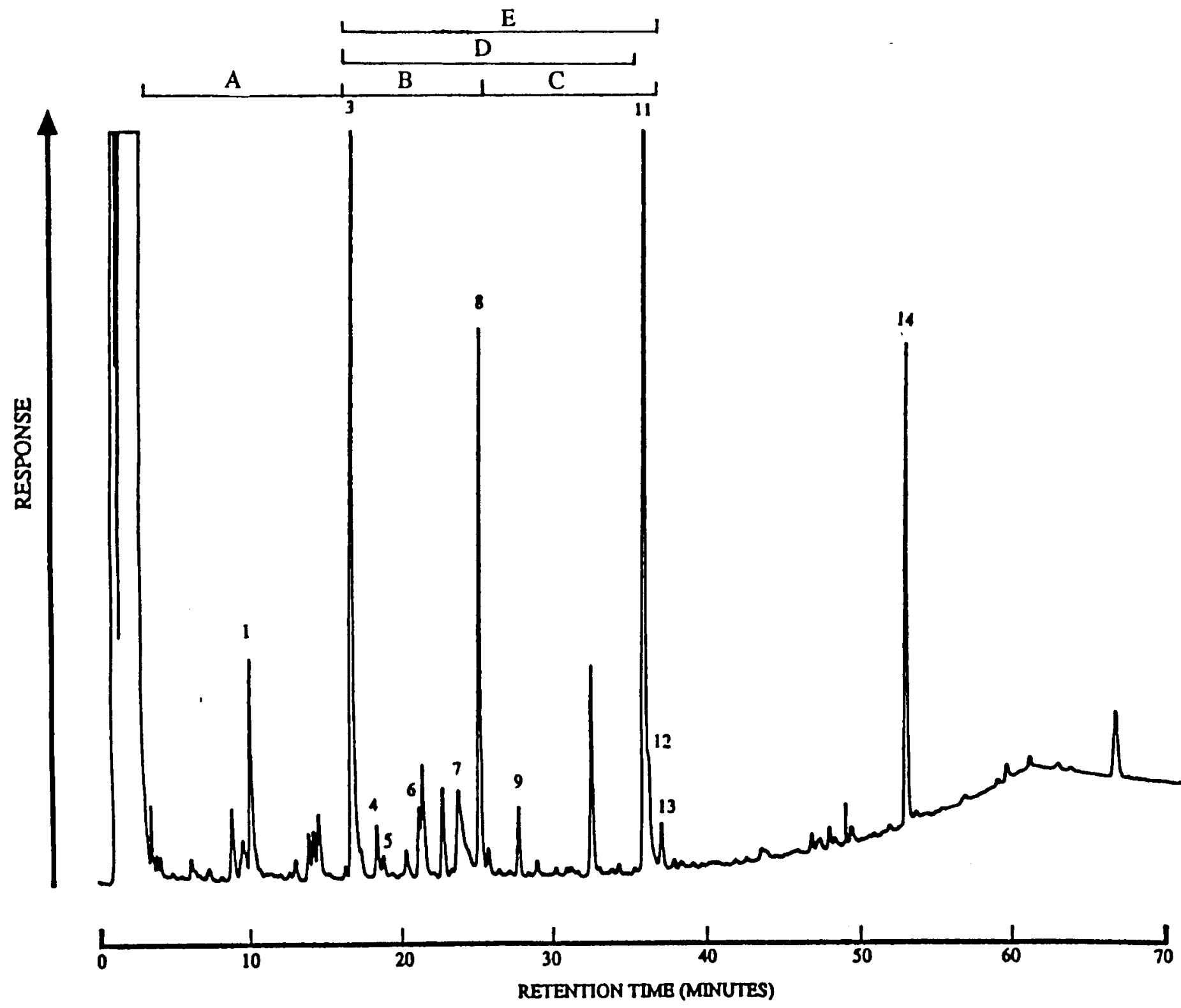

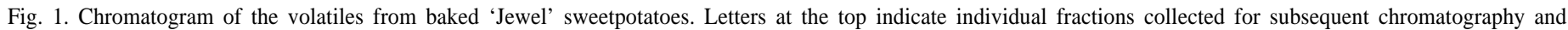
sensory analysis. Peak identification number correspond to compounds listed in Table 1. 
for volatile characterization. The GC conditions were as described previously. MS conditions were electron multiplier at $2200 \mathrm{mV}$, mass range from 40 to $300 \mathrm{amu}$, GC interface at $280 \mathrm{C}$.

Preparative GC for fractionation of baked sweetpotato volatiles. Two hundred microliters of the volatile extract of conventionally baked sweetpotato was injected into a HP 5720 GC equipped with a thermal conductivity detector (TCD). GC conditions were $10 \%$ Carbowax 20M-TPA glass column $(3.8 \mathrm{~cm}$ id. $\mathrm{x}$ $10 \mathrm{~m}$; 80/100 mesh Chromosorb WAW; initial oven temperature was $40 \mathrm{C}$ and then increased to $200 \mathrm{C}$ at $6 \mathrm{C} / \mathrm{min}$ injection port temperature $175 \mathrm{C}$, detector temperature $250 \mathrm{C}$, and TCD operated at $250 \mathrm{mV}$. Helium was used as the carrier and reference gas at 20 $\mathrm{ml} \cdot \mathrm{min}^{-1}$. A glass capillary tube (1.6 to $1.8 \mathrm{~mm}$ i.d. $\times 100 \mathrm{~mm}$ ) was placed at the exit port of the thermal conductivity detector and covered with dry ice. The volatiles, as they eluted from the column, were separated into 5 fractions: A-volatiles eluting before furyl aldehyde (Fig. 1); B- volatiles eluting from furyl aldehyde through furfuryl alcohol; $\mathrm{C}$ - volatiles eluting after furfuryl alcohol through maltol; D-volatiles eluting from furyl aldehyde through maltol; E-volatiles eluting from furyl aldehyde and before maltol. Immediately after collection, the capillary tube was sealed inside a screw cap glass test tube for subsequent sensory analysis. Similar fractions were collected and capillary tubes were rinsed with $30 \mu \mathrm{l}$ methylene chloride for gas chromatographic analysis.

Sensory evaluation. Fractions obtained from preparative GC of baked sweetpotato volatiles were evaluated using a group of five panelists, each with extensive experience in volatile research. Individual fractions were randomly labeled and each panelist was asked to compare the aroma of each fraction against that of baked sweetpotatoes. The baked sweetpotato sample consisted $20 \mu \mathrm{l}$ of the volatiles from conventionally baked sweetpotato similarly held within a capillary tube placed inside a screw-cap test tube. All samples were identical in their appearance and panelists were asked to evaluate the sample based solely on the odor perceived. Panelists assessed the similarity of the aroma between the individual fractions and the baked sweetpotato sample using a scale of very similar, similar, and different. The results were expressed as the percentage of panelists selecting a given category.

\section{Results and Discussion}

Volatile compounds identified from conventionally baked and thermolyzed sweetpotatoes were very similar except for the presence

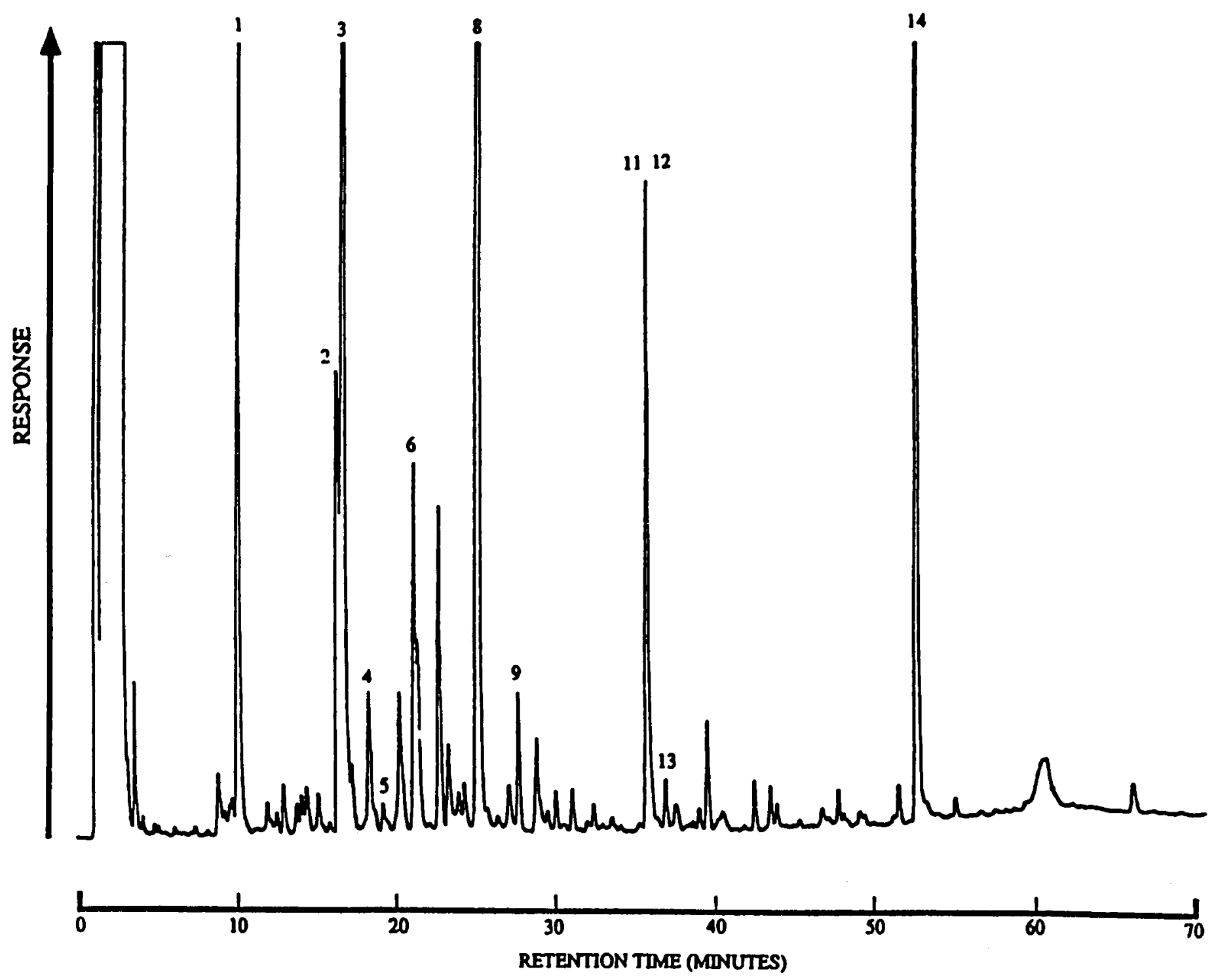

Fig. 2. Chromatogram of the volatiles from thermolyzed 'Jewel' sweetpotatoes. Peak identification numbers correspond to compounds listed in Table 1. 

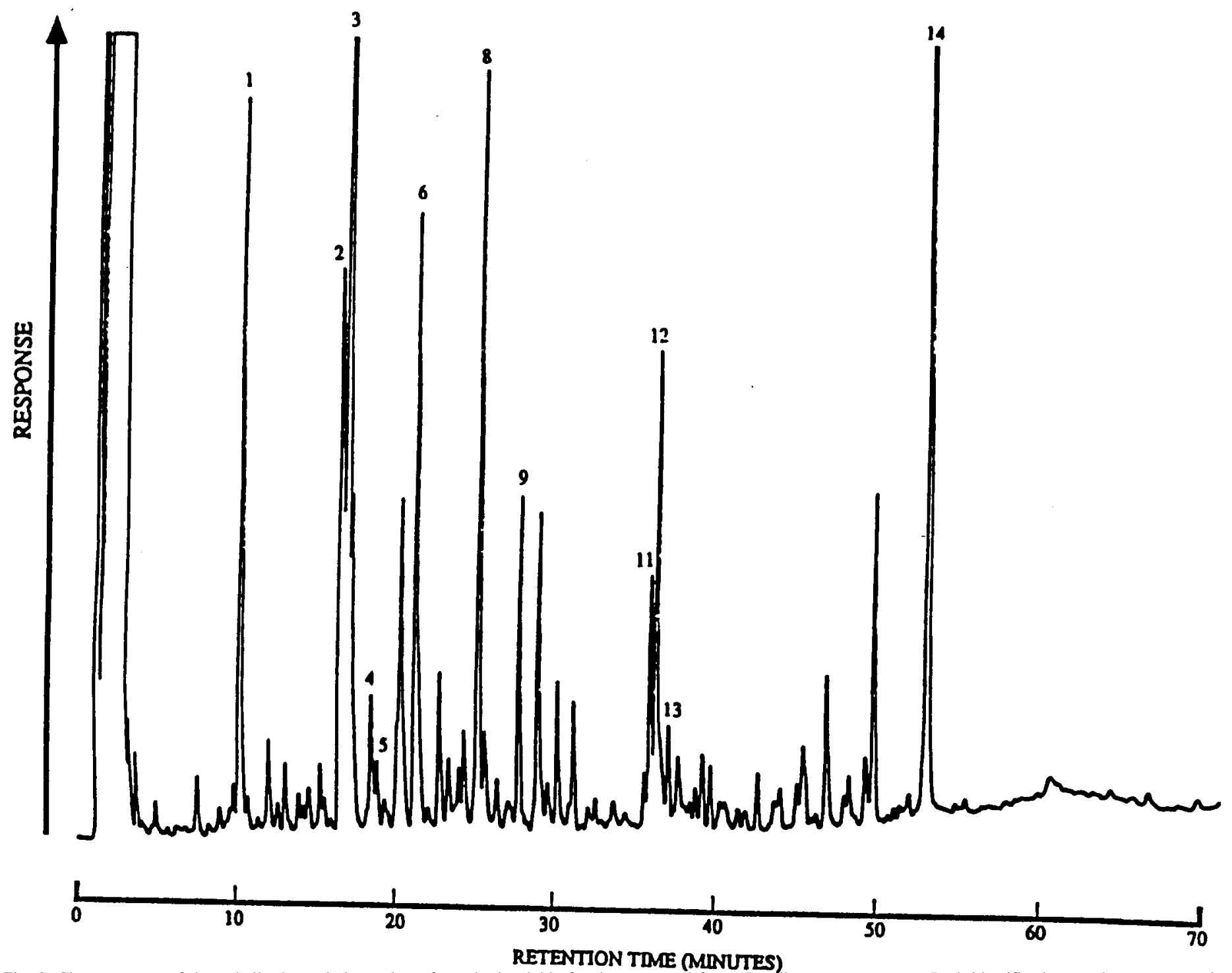

Fig. 3. Chromatogram of the volatile thermolytic products from the insoluble fraction extracted from 'Jewel' sweetpotato roots. Peak identification numbers correspond to compounds listed in Table 1.

Table 1. Volatile thermolytic products identified from sweetpotatoes, sweetpotato fractions, and sugar standards.

\begin{tabular}{|c|c|c|c|c|c|c|c|c|}
\hline \multirow{2}{*}{$\begin{array}{l}\text { reak } \\
\text { no. }\end{array}$} & \multirow[b]{2}{*}{. Compound } & \multicolumn{2}{|c|}{ Sweetpotato ${ }^{2}$} & \multicolumn{3}{|c|}{ Fraction } & \multicolumn{2}{|c|}{ Sugar } \\
\hline & & Baked & Thermolysis & Insoluble & Nonpolar & Polar & Maltose & Standard \\
\hline$\overline{1}$ & Acetol & $+^{x}$ & + & + & + & + & + & + \\
\hline 2 & Acetic acid & - & + & + & - & - & - & - \\
\hline 3 & Furyl aldehyde & + & + & + & + & + & + & + \\
\hline 4 & 2-Acetylfuran & + & + & + & - & - & + & + \\
\hline 5 & Benzaldehyde & + & + & + & - & - & - & - \\
\hline 6 & 5-Methyl-2-furfural & + & + & + & + & + & + & + \\
\hline 7 & Phenylacetaldehyde & + & - & - & - & - & - & - \\
\hline 8 & Furfuryl alcohol & + & + & + & + & + & - & + \\
\hline 9 & 3,4-Dihydropyran ${ }^{w}$ & + & + & + & - & - & - & + \\
\hline 10 & $\beta$-Ionone & - & - & - & + & - & - & - \\
\hline 11 & 3-Hydroxy-2-methyl-4-pyrone (maltol) & + & + & + & - & - & - & - \\
\hline 12 & Unknown & + & + & + & - & - & + & + \\
\hline 13 & 2-Hydroxyacetyl furan ${ }^{\mathrm{w}}$ & + & + & + & - & - & - & + \\
\hline 14 & 5-Hydroxymethyl-2-furfural & + & + & + & - & + & + & + \\
\hline
\end{tabular}

${ }^{2}$ See text for description of individual samples.

${ }^{y}$ Volatiles were listed according to their retention order on an OV-351 capillary column.

× Present, - not detectable.

"Tentatively identified using mass spectral data. 


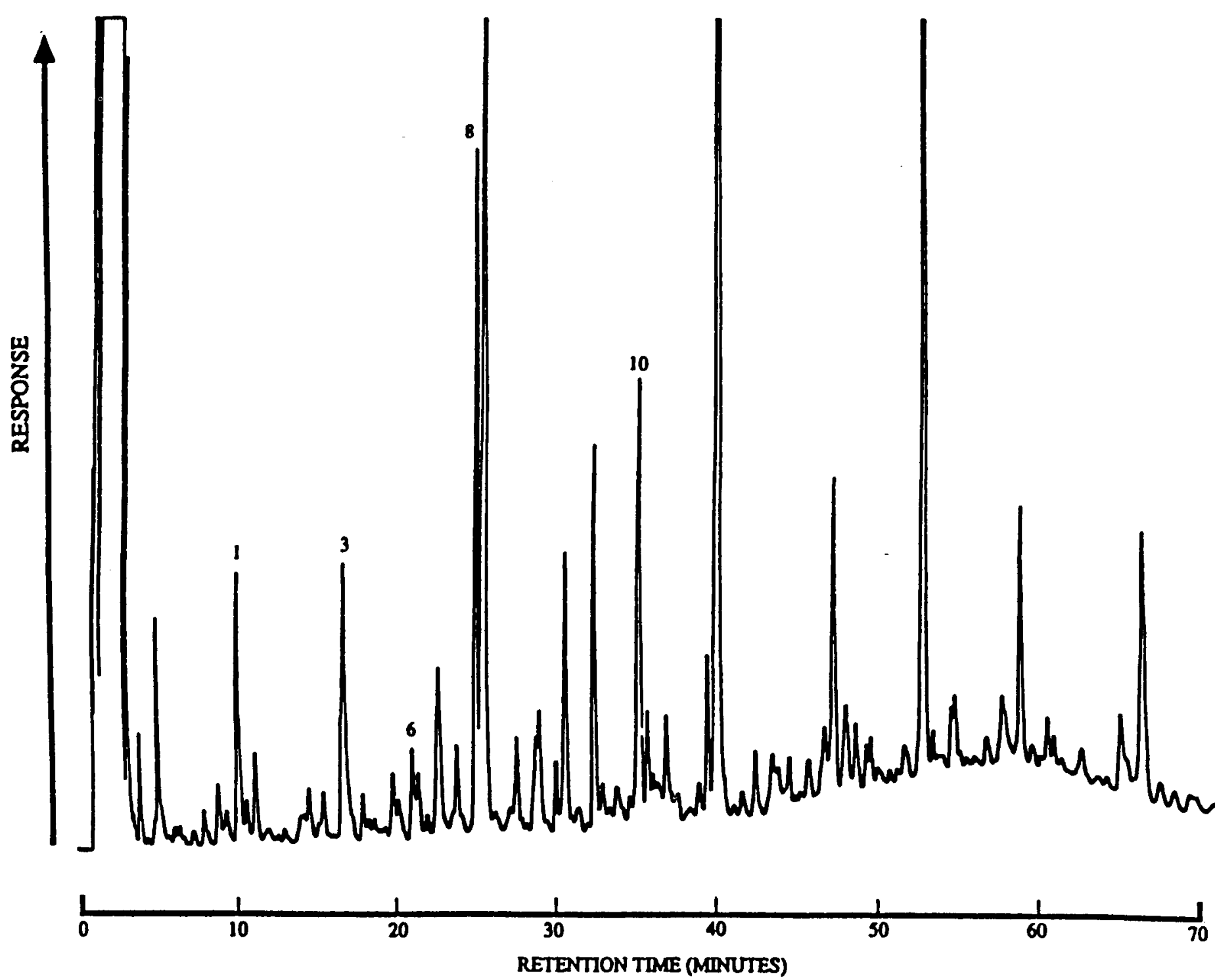

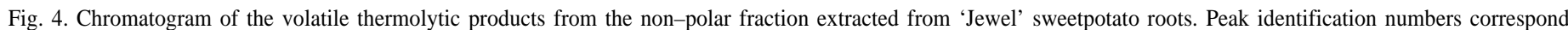
to compounds listed in Table 1

of acetic acid (thermolyzed sweetpotato) and phenylacetaldehyde (baked sweetpotato) (Figs. 1 and 2; Table 1). To determine possible precursors of the volatiles formed during baking, the volatile thermolytic products from the three fractions of sweetpotato roots (insoluble, polar, and nonpolar fractions) and unextracted root material were analyzed by GC-MS. The insoluble fraction was a white powder-like substance. The nonpolar fraction was a deep orange oily mixture and the polar fraction was a brown sticky substance. Although we did not attempt to analyze the composition of the individual fractions, based on previous work (Collins and Walter, 1985; Kays, 1992) the insoluble fraction contained starch, cellulose, hemicellulose, protein, and other insoluble, high-molecular-weight components; the nonpolar fraction was composed of B-carotene and other nonpolar lipids. A previous report indicated that the polar fraction was composed of sugars, e.g., fructose, glucose, and sucrose, and other polar compounds (Sun et al., 1994). Further analysis of the nonpolar fraction showed that it contained only traces of fructose, glucose, and sucrose.

Volatile thermolytic products identified from the insoluble fraction were qualitatively similar to those from thermolyzed sweetpotatoes (Fig. 3, Table 1); however, phenylacetaldehyde was absent in the insoluble fraction. Since the volatiles produced from the insoluble fraction were similar to those from thermolyzed sweetpotato, substances in this fraction appear to represent a primary source of precursors for the aroma of baked sweetpotatoes.

Thermal degradation of the polar fraction produced acetol, furyl aldehyde, furfuryl alcohol, and 5-hydroxymethyl-2-furfural (HMF) (Table 1). The major components of the polar fraction included fructose, glucose, and sucrose (Sun et al., 1994) and the volatiles identified were typical sugar-derived volatiles (Schlotzhauer et al., 1985; Tressl et al., 1979). Based on the absence of a number of the volatiles in the polar fraction found in the sweetpotato sample, components within the polar fraction did not appear to significantly contribute to the overall volatile profile.

Volatiles identified from the nonpolar fraction included acetol, furyl aldehyde, 5-methyl-2-furfural, furfuryl alcohol, and B-ionone (Fig. 4; Table 1). Acetol, furyl aldehyde, 5-methyl-2-furfttral, and furfuryl alcohol appear to be synthesized from sugars (glucose, fructose, and sucrose). Based upon the presence of $\beta$-carotene in the nonpolar fraction, volatiles derived from the thermal degradation of B-carotene would be anticipated. Of the typical $\beta$-carotene thermal degradation volatiles (Kanasawud and Crouzet, 1990), only B- 


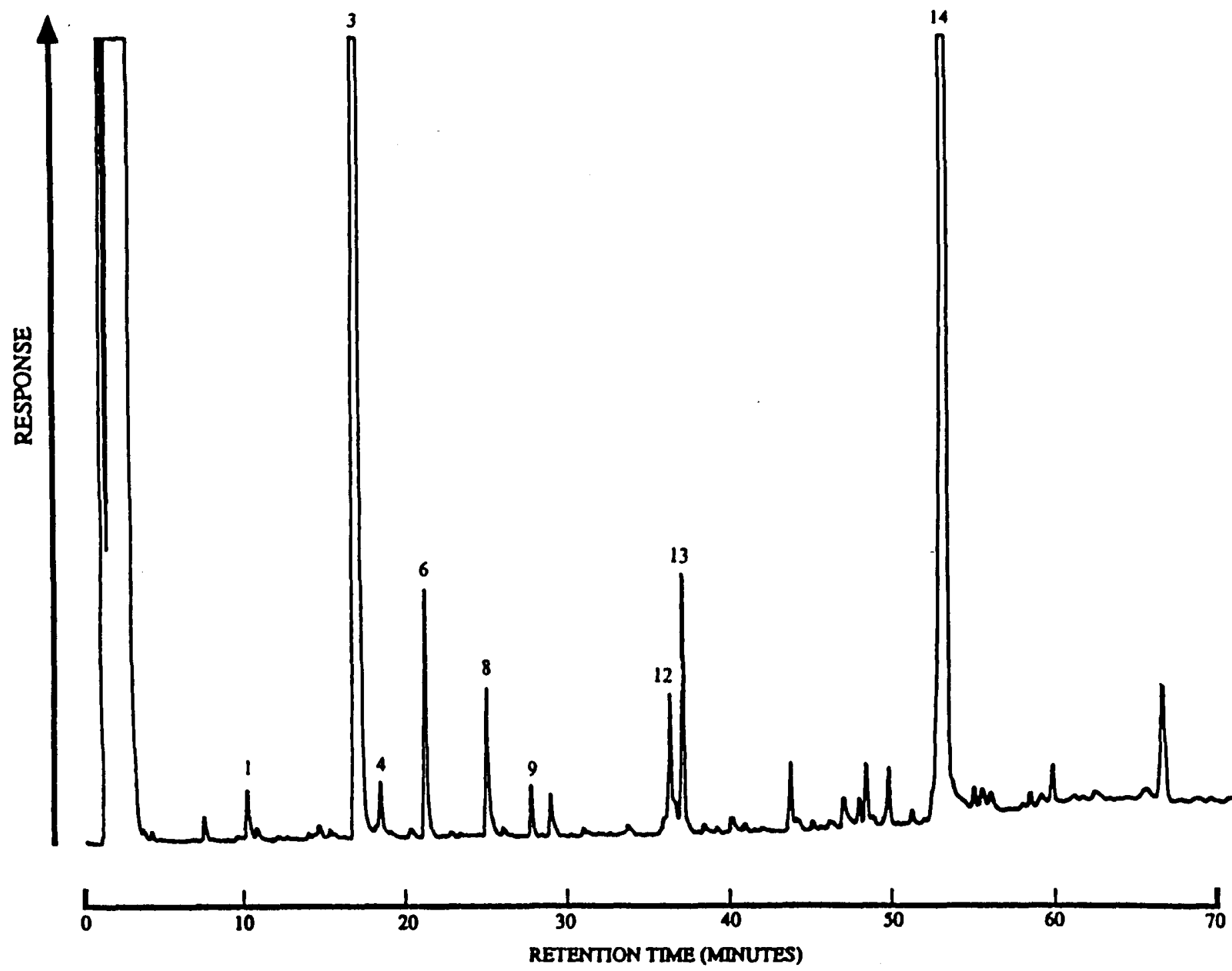

Fig, 5. Chromatogram of the volatile thermolytic products from a sugar standard, Peak identification numbers correspond to compounds listed in Table 1.

ionone was found in detectable quantities. The absence of other $\beta$ carotene related volatiles might be due to the selectivity of the stationary phase used for the GC $(\mathrm{OV}-351)$ and/or the relatively small amount of sample used $(420 \mathrm{mg}$ ) for thermolysis.

Compounds identified from the thermal degradation of the sugar standard included several typical sugar-derived volatiles (Fig. 5, Table 1). In addition, thermal degradation of maltose produced acetol, furyl aldehyde, 2-acetylfuran, 5-methyl-2-furfural, and 5-hydroxymethyl-2 -furfural (Table 1 ). Comparison of the volatiles produced by the sugar standard with thermolyzed sweetpotatoes indicated both had qualitatively similar profiles though acetic acid, benzaldehyde, and maltol were not formed with the sugar standard.

Volatiles collected from sweetpotatoes baked in a conventional convection oven were fractionated using preparative GC. Distribution of individual fractions is illustrated in Fig. 1. The elution order of the volatiles from the preparative GC was the same as that from the capillary GC. Preparative GC volatiles whose retention time was later than maltol could not be collected due to the upper temperature limit of Carbowax-20. Panelists for the sensory evaluation classified individual samples as very similar, similar, or different from the odor of volatiles from baked sweetpotatoes. To test the variation among panelists, they were asked to compare two identical control samples of baked sweetpotato aroma. All the panelists described both samples as either similar or very similar. Volatiles eluting before furyl aldehyde (fraction A) were characterized as different from the aroma of baked sweetpotatoes, indicating that relatively low-molecularweight volatiles were not critical in the characteristic aroma. Fraction B displayed a caramel-like aroma; however, it was not considered similar to the baked sweetpotato aroma; $40 \%$ of the panelists describe fraction $\mathrm{B}$ as different. Fractions $\mathrm{C}$ and $\mathrm{E}$ were described as either similar or very similar to the aroma of baked sweetpotatoes. In fraction $\mathrm{D}$, comparable to fraction $\mathrm{E}$ without maltol, the aroma of baked sweetpotato was absent; $80 \%$ of the panelists described the odor as different from the aroma of baked sweetpotatoes. Both fractions that contained maltol (fractions $\mathrm{C}$ and $\mathrm{E}$ ) were considered to more closely resemble the aroma of baked sweetpotato. Maltol, therefore, appeared to be a critical component of the characteristic aroma. Since the odor of maltol was not identical to that of baked sweetpotatoes, it was concluded that the characteristic aroma is composed of two or more volatiles, of which maltol is a key component.

Maltol was found only in the insoluble fraction and thermolyzed sweetpotatoes. The thermal degradation products of sugars, with or without maltose, were devoid of maltol. These results indicate that the formation of maltol is dependent upon substances other 


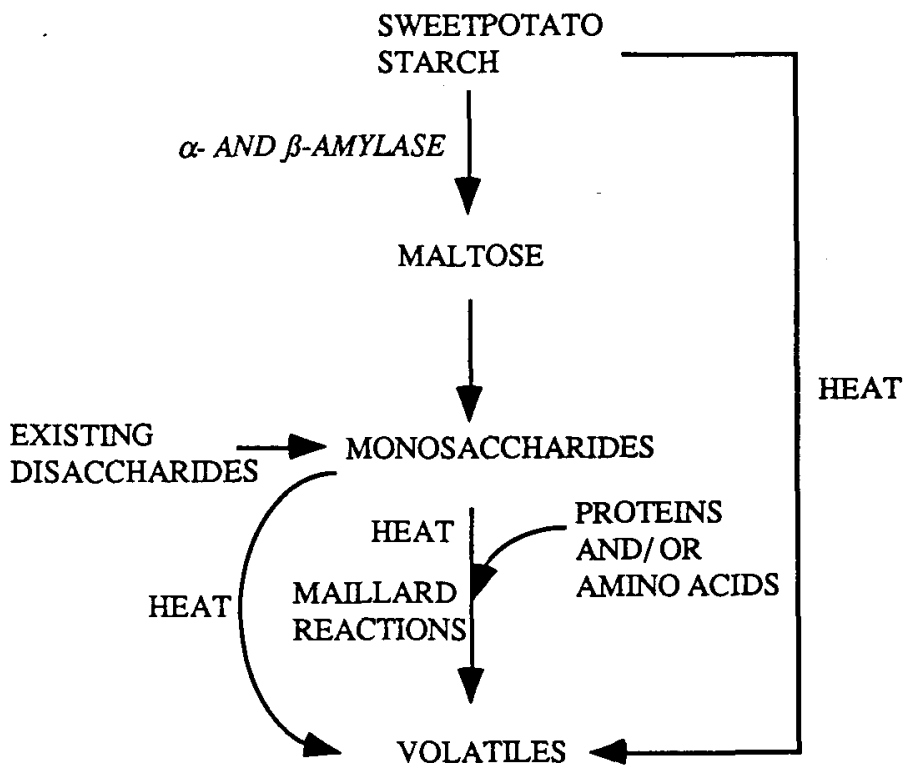

Fig. 6. Proposed pathway for the synthesis for the sweetpotato volatiles formed during baking.

than or in addition to sugars. A previous report indicated that maltose was the efficient precursor for maltol in the presence amino acids (Tress] et al., 1981, 1989). An amino-carbonyl reaction appears, therefore, to be critical for the synthesis of maltol and the characteristic aroma of baked sweetpotatoes. 1Deoxyhexosone, a methyl dicarbonyl intermediate derived from amadori compounds, has been proposed to be a common precursor of maltol, which is formed upon the release of two molecules of water (Tressl et al., 1981). Since the volatile thermolytic products from the sugar standard and maltose did not contain maltol, it would appear that the synthesis requires the presence of an appropriate nitrogen source, e.g., amino acids or proteins.

Maltose has been proposed as a critical substrate in the synthesis of baked sweetpotato volatiles (Sun et al., 1994). It is concluded that the synthesis of the characteristic aroma of baked sweetpotatoes involves both enzymatic and thermal reactions. A generalized pathway is presented in Fig. 6 . Through the activity of $\alpha-$ and $\beta-$ amylase, starch is first hydrolyzed to maltose and then to reducing monosaccharides. Proteins and/or amino acids provide the nitrogen source as the monosaccharides undergo the Maillard reaction, leading to the formation of a cross-section of volatile compounds. Other than the volatiles produced via the Maillard reaction, other thermal degradation reactions (e.g., caramelization) may contribute to the volatiles formed.

Although the Maillard reaction appears to be the operative means of synthesis of at least one critical volatile (i.e., maltol), the precise sequence of reactions is not clear. The formation of maltol is thought to occur via enolization and dehydration from reducing monosaccharides in the presence of cc-amino acids (Tressl et al., 198 1), while furyl aldehyde and 5-hydroxymethyl-2-furfural are thought to be formed through the dehydration of amadori compounds (1-amino-1-deoxy-2-ketoses) and heyns compounds (1amino-2-deoxy-2-aldoses), respectively (Verin and Parkanyi, 1982). Other volatile furans and pyrans, such as furfuryl alcohol and 5-hydroxy maltol, are also frequently reported as the products of the Maillard reaction (Fors, 1983; Fujimaki et al., 1986). Further studies are necessary to fully characterize the mechanisms involved in the formation of these volatiles as well as the identification of other components critical to the aroma.

\section{Literature Cited}

Baltes, W., J. Kunert-Kirchhoff, and G. Reese. 1989. Model reactions on generation of thermal aroma compounds, p. 143-155. In: T.H. Parliment, R.J. McGorrin, and C.-T. Ho (eds.). Thermal generation of aromas. Amer. Chem. Soc., Washington D.C.

Carlin, J. T., Q.Z. Jin, T.C. Huang, C.T. Ho, and S.S. Chang. 1986. Identification of alkyloxazoles in the volatile compounds from Frenchfried potatoes. J. Agr. Food Chem. 34:621-623.

Collins, W.W. and W.M. Waker, Jr. 1985. Fresh roots for human consumption. p. 153-173. In: J.C. Bouwkamp (ed.). Sweet potato products: a natural resource for the tropics. CRC Press, Boca Raton, Fla.

Fors, S. 1983. Sensory properties of volatile Mail lard reaction products and related compounds, p. 185-286. In: G.R. Wailer and M.S. Feather (eds.). The Maillard reaction in foods and nutrition. Amer. Chem. Soc., Washington D.C.

Fujimaki, M., M. Namiki, and H. Hato. 1986. Amino-carbonyl reactions in food and biological systems. Elsevier Science Publishing Co., New York.

Horvat, R. J., R.F. Arrendale, G.G. Dull, J.G. Chapman, and S.J. Kays. 1991. Volatile constituents and sugars of three diverse cultivars of sweet potatoes [Ipomoea batatas (L.) Lam.]. J. Food Sci. 56:714-715.

Kanasawud, P. and C. Crouzet. 1990. Mechanism of formation of volatile compounds by thermal degradation of carotenoids in aqueous medium. I. ß-carotene degradation. J. Agr. Food Chem. 38:237-243.

Kays, S.J. 1992. The chemical composition of the sweetpotato, p. 201-262. In: W.A. Hill, C.K. Bonsi, and P.A. Loretan (eds.). The sweetpotato in the 21th century. Second Intl. Symp. Sweetpotatoes, Montgomery, Ala.

Kays, S. J., and R.J. Horvat. 1984. A comparison of the volatile constituents and sugars of representative Asian, Central American and North America sweet potatoes, p. 577-586. In: 6th Symp. Intl. Soc. Trop. Root Crops, Intl. Potato Center, Lima, Peru.

Nursten, H.E. 1970. Volatile compounds: the aroma of fruits, p. 239-268. In: A.C. Hulme (ed.). The biochemistry of fruits and their products. Academic Press, New York.

Parliment, T.H. 1989. Thermal generation of aromas: an overview, p. 2 11. In: T.H. Parliment, R.J. McGorrin, and C.-T. Ho (eds.). Thermal generation of aromas. Amer. Chem. Soc., Washington D.C.

Purcell, A. E., D.E. Later, and M.L. Lee. 1980. Analysis of the volatile constituents of baked "Jewel" sweet potatoes. J. Agr. Food Chem. 28:939-941.

Schlotzhauer, W. S., R.F. Arrendale, and O.T. Chortyk. 1985. The rapid pyrolytic characterization of tobacco leaf carbohydrate material. Beitr. Tabakforsch. Intl. 13:74-80.

Schlotzhauer, W.S. and O.T. Chortyk. 1981. Pyrolytic studies on the origin of phenolic compounds in tobacco smoke. Tob. Sci. 25:6-10.

Sun, J.-S., R.F. Severson, and S.J. Kays. 1993. Quantitative technique for measurement of the volatile components of baked sweetpotatoes. HortScience 28:1110-1113.

Sun, J.-S., R.F. Severson, and S.J. Kays. 1994. Effect of heating temperature and microwave pretreatment on the formation of sugars and volatiles in Jewel sweetpotato. J. Food Qual. 17:447456.

Tiu, C. S., A.E. Purcell, and W.W. Collins. 1985. Contribution of some volatile compounds to sweet potato aroma. J. Agri. Food Chem. 33:223-226.

Tressl, R., B. Helak, N. Martin, and E. Kersten. 1989. Formation of amino acid specific Maillard products and their contribution to thermally generated aromas, p. 156171. In: T.H. Parliment, R.J. McGornn, and C.-T. Ho (eds.). Thermal generation of aromas. Amer. Chem. Soc., Washington, D.C.

Tressl, R., K.G. Grünewald, and B. Helak. 1981. Formation of flavour components from proline and hydroxyproline with glucose and maltose and their importance to food flavour, p 397416. In: P. Schreier (ed.). Flavour' 81 . Walter de Gruyter, New York.

Tressl, R., K.G. Grünewald, R. Silwar, and D. Bahri. 1979. Chemical formation of flavour substances, p. 197-213. In: D.G. Land and H.E. Nursten (eds.). Progress in flavour research. Applied Science Publisher, London.

Vemin, G. and C. Parkanyi. 1982. Mechanisms of formation of heterocy clic compounds in Maillard and pyrolysis reactions, p. 151 -207. In: G. Vemin (ed.). Chemistry of heterocyclic compounds in flavours and aromas. Ellis Horwood Limited, West Sussex, England. 